\title{
PV Optimized Control of Modulating Heat Pumps regarding PV Self-Consumption
}

\author{
Christina Betzold, Arno Dentel \\ Technische Hochschule Nuremberg Georg Simon Ohm, Nuremberg, Germany
}

\begin{abstract}
As the feed-in tariff of PV reduces (Wirth, H., 2018), the $\mathrm{PV}$ self-consumption becomes more profitable. Heat pumps can contribute to increase PV self-consumption because they can transform electrical power to heat and store the PV surplus in form of thermal power. Furthermore, heat pumps, which are able to modulate the compressor speed, open up more flexibility and adaption to the fluctuating PV power and to the thermal load profile of buildings. For exploiting the full potential, a smart control for modulating heat pumps (MHPs) is needed.

This paper describes the development and the real application of a PV optimized control for MHPs in plus energy terraced houses, built in 2017. The PV optimized control was tested in terraced houses in winter 2018 and validated in the simulation software TRNSYS (2018). The first measurements of the MHP system show an accordance with the simulation results. The NRMSD value for the thermal power of the MHP model is between $5.4 \%$ and $7.7 \%$. Within the validation of the MHP System, the NRMSD value for temperatures in storage tanks is up to $29.4 \%$. The NRMSD for the PV selfconsumption is $1.65 \%$.
\end{abstract}

\section{Introduction}

Since the feed-in tariff of PV decreased, the focus is on control strategies, which enables an increase of PV selfconsumption. Battaglia, M. et al. (2017) show, how control strategies for overheating thermal storage tanks can reduce costs for electricity. Psimopoulos et al. (2016) investigates control algorithms in terms of its impact on final energy, solar fraction, self-consumption and seasonal performance factor in the simulation software TRNSYS. Results show an increase of PV selfconsumption to $50.5 \%$ by using control strategies in combination with thermal and electrical storage.

Developed control strategies in simulation studies may vary from implemented control strategies as components are configurated with different input parameters from manufacturers. This leads to a changed control strategy in real application. In order to verify the implemented control strategy in a real application, the simulation model has to be validated to the real components. Buderus et al (2017) show a method to validate a buffer storage model to measurements from a hardware test bench. Banister et al. (2014) show a validation of the heat pump system model in TRNSYS, which was compared to a purposebuilt experimental test apparatus.

In a previous simulation study, a control strategy, the Demand Side Management System (DMS), for the terraced houses was developed and is described in (Dentel, A. et al., 2017), but during the implementation, the control strategy was changed due to different configuration input parameters from the manufacturers. This lead to an adaption of the DMS to the Energy System and the PV optimized control was developed. The PV optimized control includes the controlling of heat pumps and the battery in the energy system. The energy concept of the terraced houses consists of two shared MHPs, connected to a two storage cascade, eight decentralized domestic hot water heat pumps (DHW-HPs) with a 200 liters storage each and a shared battery. The second surplus storage in the storage cascade has a volume of 2000 liters and is charged only during PV production. The first buffer storage has a size of 800 liters and is charged during grid and $\mathrm{PV}$ consumption.

The focus of this investigation is on the MHPs and the buffer storage tanks as a part of the whole Energy System and its contribution to the PV self-consumption. The paper discusses the approach of controlling the MHPs in simulation and in real application.

\section{Methods}

\section{Control Strategy}

The PV optimized control aims to operate the MHPs in order to maximize the PV self-consumption and to increase the Coefficient of Performance (COP) during grid consumption.

The PV optimized control is implemented as a rule base control. First, as there is a surplus of PV power, after fulfilling the electricity needs of the household, the main focus of the PV optimized control is on the adaption of the compressor speed of the MHPs to PV surplus power. During grid consumption, the MHPs operate in part load because of the higher efficiency.

In simulation the compressor speed is an input of the heat pump model and is calculated by the available $\mathrm{PV}$ power and the polynomial of the MHP, shown in Equation (7). Thus, the compressor speed can be adapted to the PV power exactly. However, in real application the compressor speed cannot be set directly by the PV optimized control. The manufacturer offers the possibility to set the set temperature of the return flow. Then, the 
internal control of the MHP controls the compressor speed in order to reach the same temperature for actual and set temperature of the return flow. This concept don't allow an exact control of the compressor speed and thus an exact adaption to the available PV power is not possible.

The PV optimized control has 4 operation modes for the MHPs depending on the grid consumption and the available PV power.

1. Grid Mode: During the develepement in simulation, the modulation of the MHPs is supposed to be $40 \%$ of the heating power. In real application, the set temperature of the return flow is $30{ }^{\circ} \mathrm{C}$ and the modulation changes according to the actual temperature, consequently to the demand of the thermal load. This leads to a supply temperatue of the MHPs of $32{ }^{\circ} \mathrm{C}-35^{\circ} \mathrm{C}$, because the supply temperature of the building has to be at least $30^{\circ} \mathrm{C}$.

2. PV Mode: During the developement in simulation, the PV optimized control adapts the compressor speed to the available PV power by calculating the modulation using the polynomial of the MHP, shown in Equation (7). This leads to a modulation between $18 \%$ and $100 \%$ of the heating power and an exact adaption to PV power. The exact implementation of this function is not possible in a real application. The PV Mode starts in the real system, when the PV power after household consumption is above $3 \mathrm{~kW}$. Then the set temperature of the return flow is set to $35{ }^{\circ} \mathrm{C}$. In the PV Mode a second buffer storage is charged as well until the temperature at the bottom reaches $35^{\circ} \mathrm{C}$.

3. Load Management: The Load Management aims to avoid electrical load peaks of the terraced houses. During the develepement in simulation and in real application, the PV optimized control switches the MHPs off for 15 minutes, if a load peak of $16 \mathrm{~kW}$ is reached.

4. Priority Mode: This mode ensures that the thermal comfort in the terraced houses is fulfilled at all times. In simulation, the Priority Mode starts, if the temperature falls under $27{ }^{\circ} \mathrm{C}$ in the first buffer storage and then, the modulation is set to $70 \%$. In real application, the set temperature of the return flow of the MHPs is set to $32{ }^{\circ} \mathrm{C}$ when the temperature falls under $27^{\circ} \mathrm{C}$ in the first buffer storage tank. This mode is normally coupled to the Load Management.

\section{Modulation Heat Pumps}

Besides the flexibility to PV power operation, the modulation also has a benefit of energy efficiency. The MHP inverter performance characteristic leads to a COP optimized operation in part-load operation. Figure 1 shows the heating and the COP curve of the MHP for an evaporator temperature of $5^{\circ} \mathrm{C}$ and a condenser temperature of $35^{\circ} \mathrm{C}$. It is visible that the highest efficiency (max. COP) is at a modulation speed of $40 \%$. The PV optimized control enables an optimization of the modulation speed of the two MHPs with respect to the COP and the actual produced PV power.

The existing TRNSYS Type 401 from Afjei and Wetter (1997) provides an on/off heat pump that was extended and validated for modelling the modulating heat pumps and is described in (Dentel, A. et al., 2017). This lead to the introduction of the TRNSYS Type 4010 that offers a modulation speed as input, additionally.

The bi-quadratic-polynomial equation for describing the heat pump characteristics is extended by the modulation speed $\left(Y_{n, i}\right)$. Equation (1) shows the new polynomial equation $\left(P_{i}\right)$ for calculating the electrical power with eight coefficients $\left(b p_{n}\right)$, the evaporator inlet temperature $\left(\varphi_{x, e v, i n, i}\right)$, the condenser outlet temperature $\left(\varphi_{x, \text { cond out }, i}\right)$, and the modulation speed $\left(Y_{n, i}\right)$. The thermal power $\left(Q_{i}\right)$ is represented by the polynomial, shown in Equation (2), with eight coefficients $\left(b q_{n}\right)$, the evaporator inlet temperature $\left(\varphi_{x, e v, i n, i}\right)$, the condenser outlet temperature ( $\left.\varphi_{x, \text { cond,out } i}\right)$, and the modulation speed $\left(Y_{n, i}\right)$. Table 1 gives an overview of the root-mean-square-deviation (RMSD) for the validation of the polynomial equation. The RMSD shows good accordance for evaporator, compressor and condenser power, compared to the manufacturer data.

$$
\begin{aligned}
& P_{i}=b p_{1}+b p_{2} \cdot \varphi_{x, e v, i n, i} \cdot Y_{n, i}+b p_{3} \cdot \varphi_{x, \text { condout }, i} \cdot Y_{n, i} \ldots \\
& +b p_{4} \cdot Y_{n, i}+b p_{5} \cdot \varphi_{x, e v, i n, i} \cdot \varphi_{x, \text { cond,out }, i} \cdot Y_{n, i}+b p_{6} \cdot \varphi_{x, e v, i n, i}{ }^{2} \cdots \\
& +b p_{7} \cdot \varphi_{x, \text { cond,out }, i}{ }^{2}+b p_{8} \cdot Y_{n, i}{ }^{2} \\
& Q_{i}=b q_{1}+b q_{2} \cdot \varphi_{x, e v, i n, i} \cdot Y_{n, i}+b q_{3} \cdot \varphi_{x, \text { cond,out }, i} \cdot Y_{n, i} \ldots \\
& +b q_{4} \cdot Y_{n, i}+b q_{5} \cdot \varphi_{x, e v, i n, i} \cdot \varphi_{x, \text { cond,out }, i} \cdot Y_{n, i}+b q_{6} \cdot \varphi_{x, e v, i n, i}{ }^{2} \cdots \\
& +b q_{7} \cdot \varphi_{x, \text { cond,out }, i}{ }^{2}+b q_{8} \cdot Y_{n, i}{ }^{2}
\end{aligned}
$$

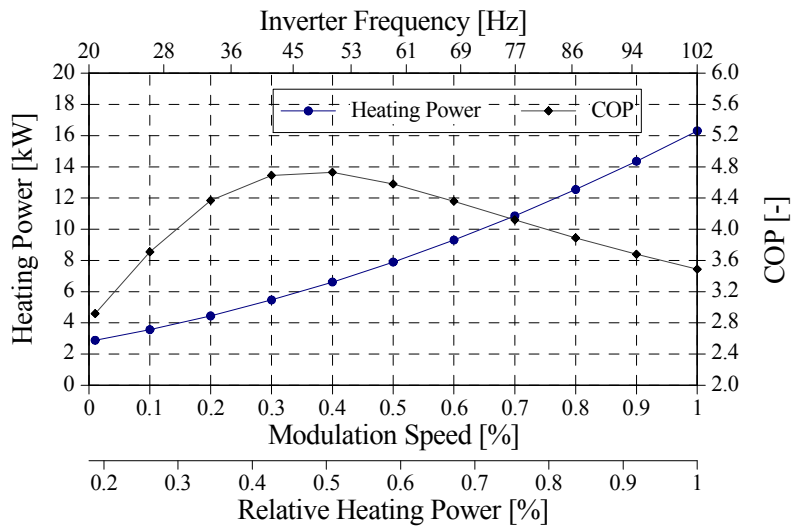

Figure 1: Heating power and COP over the modulation speed, inverter frequency, and relative heating power of the heat pump for $5^{\circ} \mathrm{C} / 35^{\circ} \mathrm{C}$. 
Table 1: Validation data of the MHP-RMSD values.

\begin{tabular}{|c|c|}
\hline evaporator power & $0.6326 \mathrm{~kW}$ \\
\hline compressor power & $0.1072 \mathrm{~kW}$ \\
\hline condenser power & $0.7026 \mathrm{~kW}$ \\
\hline
\end{tabular}

\section{Measurements}

For evaluating the PV optimized control, the MHP system is monitored at all energy balance limits. Figure 2 shows the layout of the MHP System and the position of the measuring points. There are temperature sensors at evaporator and condenser side of the MHPs for supply and return flow. Only the mass flow on the condenser side is measured, the mass flow at the evaporator side is calculated. For evaluating the Seasonal Performance Factor (SFP) the electrical power is monitored. The thermal power is calculated by measured condenser inand outlet temperatures and mass flow rates, shown in Equation (4). The frequency of the MHPs is measured as well. The two buffer storage units have each two temperature sensors at the top and bottom. On the building load side, there are temperature sensors for supply and return and a heat meter. The signal for the valve V7, opening the second buffer storage during PV production, is measured as well.

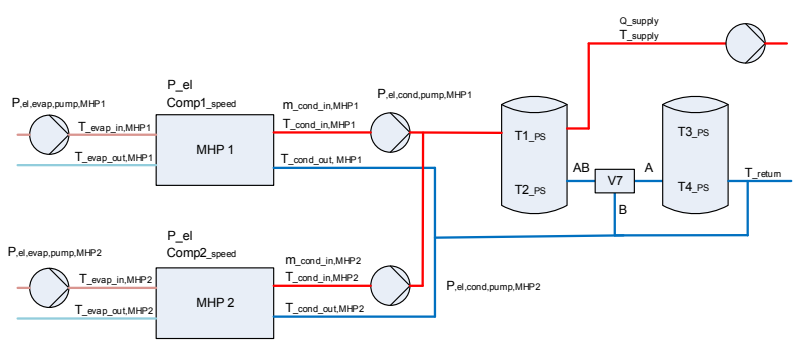

Figure 2: Measuring points of the MHP system.

The measuring points of the MHPs as well as the temperature and mass flow measurement at evaporator and condenser side are measured in a 1-minute step. The temperature of the storage units and the measurement of load temperature and energy heat are recorded in a 15minute step. The external temperature sensors are PT 100, the heat measurement is an ultrasonic meter with PT 500 temperature sensors. The accuracy of the calculator is $+/-(0.15+3 \mathrm{~K} / \mathrm{dT}) \%$. Electrical measurements are by $3-$ phase pulse counter with an accuracy of $+/-1 \%$.

Important values for evaluating the MHP System, which are not measured, are calculated. Equation (3) is for determining the compressor power of the MHP $\left(P_{e l, M H P \text {, }}\right.$ measured) without auxiliary power of the pumps of the evaporator $\left(P_{\text {el,evap, pump }}\right)$ and condenser side $\left(P_{e l, \text { cond,pump }}\right)$.

$P_{e l, \text { MHP, measured }}=P_{-e l}-P_{e l, \text { evap }, \text { pump }}-P_{e l, \text { cond }, \text { pump }}$
The calculation of the thermal power of the $\mathrm{MHP}\left(\mathrm{Q}_{t h, M H P \text {, }}\right.$ measured) is shown in Equation (4). The thermal power is a product of the heat capacity of water, the measured mass flow ( $m_{\text {cond in, } M H P, \text { Measured }}$ ) and the supply and return temperature ( $\left.T_{\text {cond in, MHP, Measured; }} T_{\text {cond out, } M H P, \text { Measured })}\right)$ of the condenser.

$$
\begin{aligned}
& \mathrm{Q}_{t h, M H P, \text { measured }}=\mathrm{c}_{p, w} * m_{\text {cond in, MHP, Measured }} * \ldots \\
& \left(T_{\text {cond in }, \text { MHP, Measured }}-T_{\text {cond out }, \text { MHP, Measured }}\right)
\end{aligned}
$$

As the mass flow of the evaporator is not measured, the calculation of the mass flow ( $\left.\mathrm{m}_{\text {evap in, } M H P, \text { Measured }}\right)$ is shown in Equation (5). The evaporator power $\left(Q_{\text {evap, } M H P, \text { measured }}\right)$ is a subtraction of thermal and electrical power, shown in Equation (6). The in- and outlet temperatures of the evaporator are measured ( $T_{\text {evap in, MHP, Measured }}$; $T_{\text {evap out, } M H P \text {, }}$ Measured).

$$
\begin{aligned}
& \mathrm{m}_{\text {evap in, MHP, Measured }}=Q_{\text {evap }, \text { MHP, measured }} / \ldots \\
& c_{p, b} *\left(T_{\text {evap in, MHP, Measured }} T_{\text {evap out }, \text { MHP, Measured }}\right)
\end{aligned}
$$

with

$$
Q_{\text {evap }, M H P, \text { measured }}=\mathrm{Q}_{t h, M H P, \text { measured }}-P_{\text {el, }, \text { MHP, measured }}
$$

The measured frequency ( $f r q$ ) of the MHP is transformed into the modulation speed $\left(Y_{n, i}\right)$, shown in Equation (7), in order to give an input to the MHP model.

$$
Y_{n, i}=-0.008193 * f r q^{2}+2.207 * f r q-39.86
$$

\section{Simulation and Validation}

As mentioned in the description of the modes in section Methods and subsection Control Strategy, there have been a few changes from the development of the DMS (Dentel et al., 2017) in simulation to the real application in the terraced houses. Thus, the PV optimized control in real application is re-implemented in simulation again in order to validate the simulation model of the MHP and the MHP system.

\section{Validation of Modulating Heat Pumps}

In the first step the model of the MHP is validated by measured data from a winter day. The model of the MHP gets inputs of the measured temperature and mass flow at evaporator ( $\left.T_{\text {evap in, MHPI/2, Measured }} ; m_{\text {evap in, MHP1/2, Measured }}\right)$ and condenser side $\left(T_{\text {cond in, MHPI/2, Measured }} ; m_{\text {cond in, MHPI/2, }}\right.$ Measured). As well, the measured frequency of the compressor speed is turned into a modulation speed by a polynomial, shown in Equation (7), and is an input of the model. 
The results of the MHP model are compared to the measurements of MHP 2 from the Energy System of the terraced houses.

Figure 3 shows that the measured condenser outlet temperature ( $\left.T_{\text {cond out, MHP2, Measured }}\right)$ as well as the simulated condenser outlet temperature ( $T_{\text {cond out, }}$ MHP2, Simulated $)$ are similar. However, during high thermal operation, the deviations increase. The same effect is visible for the measured evaporator outlet temperature ( $T_{\text {evap out, } M H P 2,}$ Measured $)$ and the simulated evaporator outlet temperature ( $T_{\text {evap out, MHP2, Simulated }}$ ) (see Figure 4$)$. The comparison of MHP 1 show the same results.

Furthermore, the measured and simulated thermal and electrical power of MHP 1 and 2 is compared. Figure 5 shows measured and simulated thermal and electrical power of the MHP 1. There is a higher measured thermal power $\left(Q_{i n, M H P 1, \text { Measured }}\right)$ until a frequency of $55 \mathrm{~Hz}$ than the simulated thermal power $\left(Q_{i n, M H P I, \text { Simulated }}\right)$. From $55 \mathrm{~Hz}$ the measured thermal power is lower than the simulated thermal power. In contrast to the thermal power, the measured and simulated electrical power $\left(\mathrm{P}_{e l}\right.$, MHPI, Measured; $\mathrm{P}_{e l,}$ MHPI, Simulated) fits better in higher frequency at $55 \mathrm{~Hz}$. In lower frequency, there is a mean offset of about $400 \mathrm{~W}$ between measured and simulated electrical power.

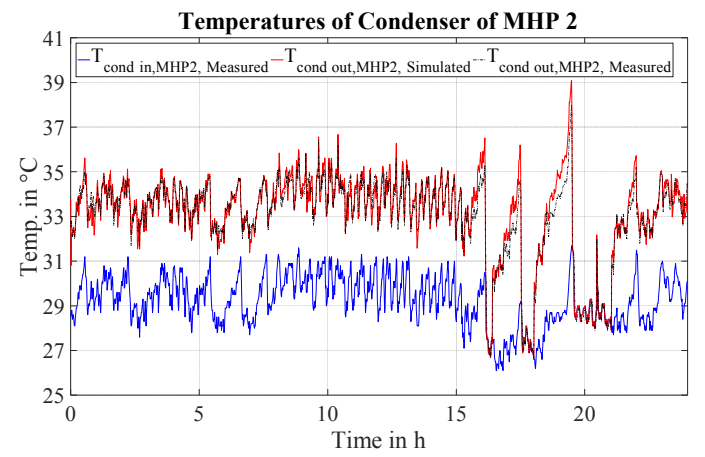

Figure 3: Temperatures of condenser of MHP 2.

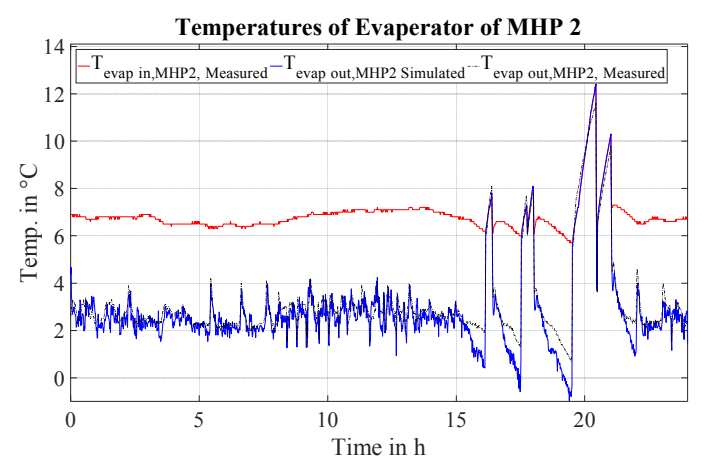

Figure 4: Temperatures of evaporator of MHP 2.

Figure 6 shows measured and simulated thermal and electrical power of the MHP 2. In contrast to MHP 1, the measured and simulated thermal power of MHP 2 is similar. During lower frequency of the compressor, the simulated thermal power ( $\left.Q_{i n, M H P 2, \text { simulated }}\right)$ fits to the measured thermal power $\left(Q_{i n, M H P 2,}\right.$ Measured $)$. In higher frequency at $55 \mathrm{~Hz}$, the deviation is up to $25 \%$. As well as MHP 1, the electrical power of MHP $2\left(\mathrm{P}_{\text {el, MHP2, Measured; }}\right.$ $\mathrm{P}_{e l, M H P 2, \text { Simulated }}$ ) fits better in higher frequency at $55 \mathrm{~Hz}$ and in lower frequency, there is a mean offset of about $400 \mathrm{~W}$ between measured and simulated electrical power.
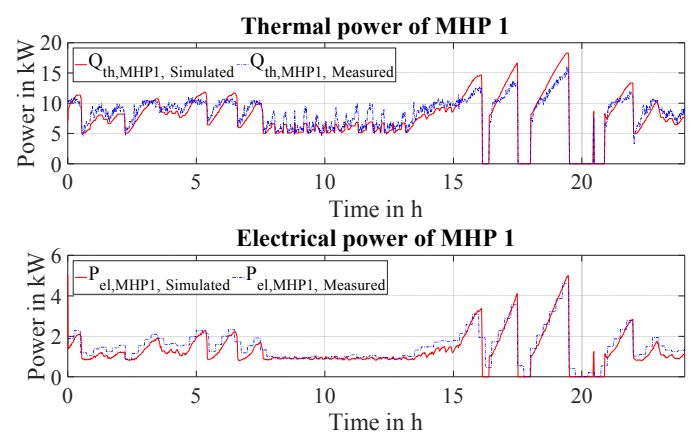

Figure 5: Thermal and electrical power of MHP 1.
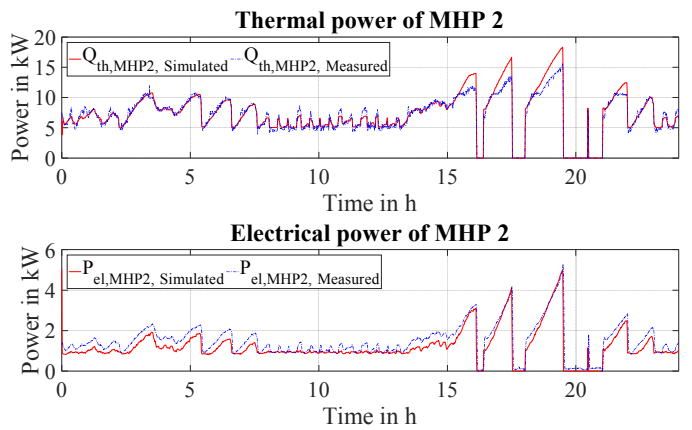

Figure 6: Thermal and electrical power of MHP 2.

As there are obvious deviations for thermal power of MHP 1, the measured data and the simulated results of MHP 1 and 2 are compared for a time period of 2 hours in which both MHPs operate at the same frequency. The set return temperature is the same for MHP 1 and 2 and is set to $30^{\circ} \mathrm{C}$.

As the thermal power is a calculation of measured in- and outlet temperatures of the condenser and the mass flow rate, Figure 7 gives an overview of the measured mass flow of MHP 1 and 2. The mass flow rate (Figure 7, bottom) differs from MHP 1 to MHP 2 at the same frequency. This leads to a higher thermal power of MHP 1. Figure 8 shows the measured and simulated thermal power of MHP 1 and 2. During the same frequency, the simulated thermal power is the same, but the measured thermal power of MHP 1 is mostly higher. There might be measuring inaccuracies and errors during the measurement of the mass flow. This leads to deviations between measured and simulated thermal power of MHP 1. 

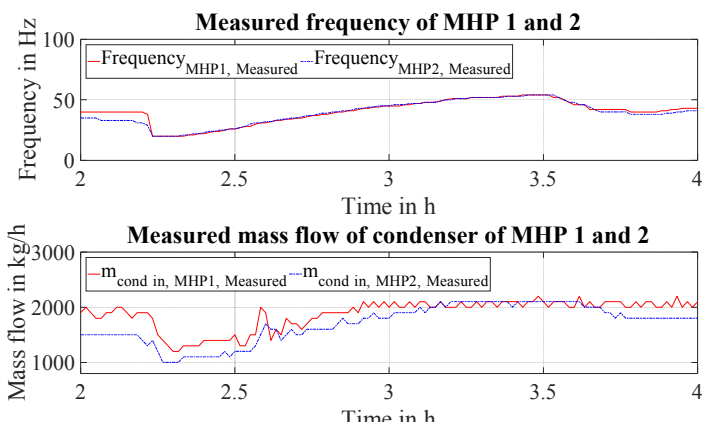

Figure 7: Comparison of measured in- and outlet mass flow of condenser of MHP 1 and 2 at same frequency.
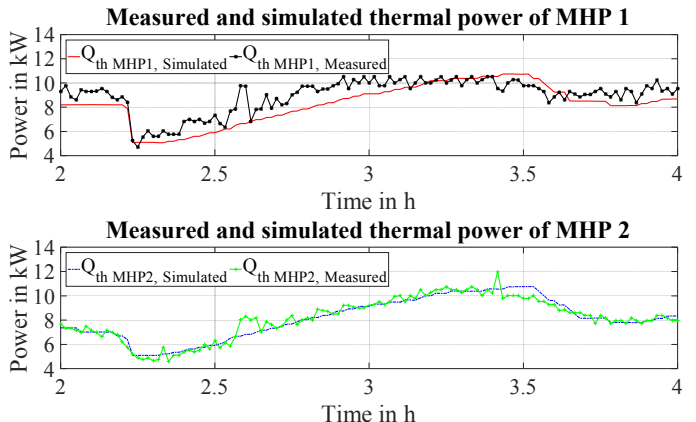

Figure 8: Comparison of measured and simulated thermal power of MHP 1 and 2 at same frequency.

\section{Validation of MHP System}

Next, the model of the MHP System is validated by measured data from the same winter day as shown in section Validation and Simulation and subsection Validation of Modulating Heat Pumps. The model of the MHPs is extended with the two storage units and the thermal building load, shown in Figure 2. In TRNSYS the storage is represented by the TYPE 534 .

As the course of the frequency is the same, the electrical and thermal power of the MHPs is also the same and can be seen in Figure 5 and 6 . Only the condenser inlet temperature of the MHPs is different as it is an input from the storage model.

Figure 9 shows the measured and simulated in- and outlet temperatures of the condenser of MHP 2. The simulated temperatures are higher than the measured temperatures. The results for MHP 1 are similar. Figure 10 presents the measured and simulated temperatures at top and bottom of buffer storage 1 and 2. The course of measured temperatures is quite between the simulated temperatures. Figure 11 shows supply and return temperatures of the building load and the heating load. The simulated supply temperature $\left(T_{\text {supply, Simulated }}\right)$ fits to the course of the measured supply temperature $\left(T_{\text {supply, } \text { Measured }}\right)$.

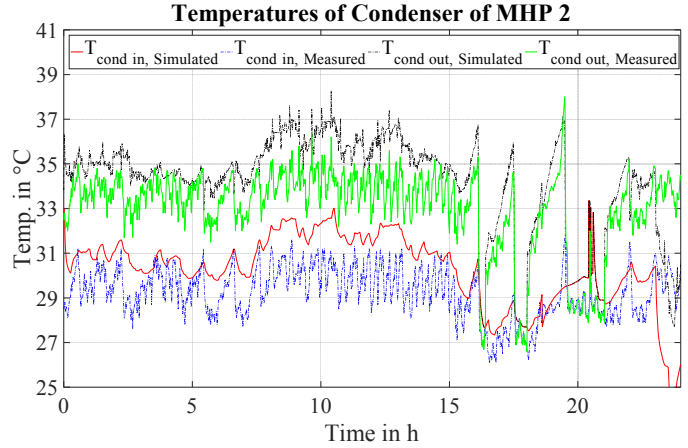

Figure 9: Measured and simulated temperatures of condenser of MHP 2 in MHP System model.
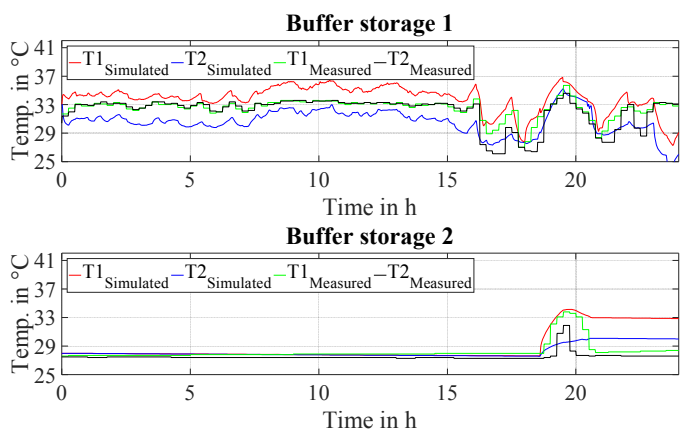

Figure 10: Measured and simulated temperatures of Buffer storage 1 and 2 in MHP System model.
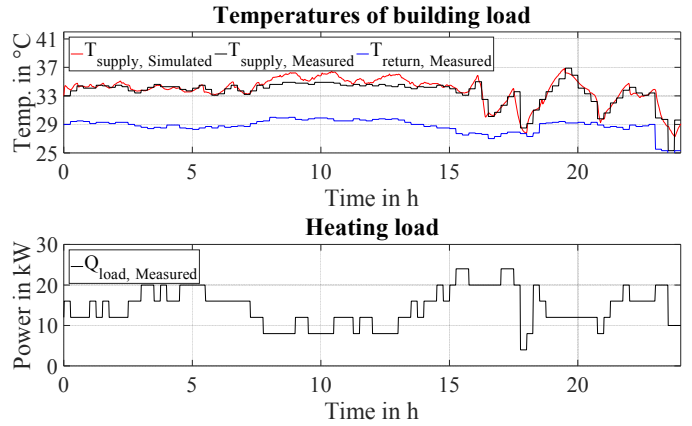

Figure 11: Measured and simulated temperatures of building load and measured heating load in MHP System model.

\section{Simulation of Operation Modes and PV Self- Consumption}

The PV optimized control offers 4 operation modes, which were used during the measured winter day. The next figures give an overview of the temperature levels in the storage units and the power of the MHPs during the different operation modes. All operation modes were used within a time period of 6 hours during the winter day. As mentioned in the description of the modes in section Methods and subsection Control Strategy, the modes depend on grid consumption and PV surplus after fulfilling the electricity needs of the household. Figure 13 shows the grid consumption $\left(P_{\text {Grid, } \text { Measured }}\right)$ and PV surplus after fulfilling the electricity needs of the household $\left(\mathrm{P}_{P V}\right.$ 
plus, Measured) as well as the measured and simulated electrical power of MHP 1. The different operation modes are marked with numbers from 1 until 4.

Operation mode 1: Grid Mode shows low thermal and electrical power of the MHP (see Figure 13 bottom) during grid consumption (see Figure 13 top). The set temperature of the return flow is set to $30{ }^{\circ} \mathrm{C}$. The temperature level in buffer storage 1 is between $30^{\circ} \mathrm{C}$ and $35^{\circ} \mathrm{C}$ (see Figure 14). Buffer storage 2 is not charged (see Figure 15).

Operation Mode 3: The Load Management was tested and the MHP was switched off for 15 minutes in order to avoid load peaks. While the Operation Mode 3 (Load Management) is active, the temperatures in buffer storage 1 decrease down to $30^{\circ} \mathrm{C}$ and lower. During the winter day, there was a function test of the Load Management and therefore, the maximal load peak was reduced to $11 \mathrm{~kW}$. Normally, the maximal load peak is set to $16 \mathrm{~kW}$.

After the enforced switch off of the MHPs during the Load Management, the temperatures decrease under $27^{\circ} \mathrm{C}$ and Operation Mode 4 (Priority Mode) is set. In this mode, the set temperature of the return flow is set to $32{ }^{\circ} \mathrm{C}$ and the MHPs operate with higher power until the buffer storage 1 reaches $32^{\circ} \mathrm{C}$ at the top.

When the PV surplus increases above $3 \mathrm{~kW}$, the Operation Mode 2 (PV Mode) is set. In this mode, the set temperature of the return flow is set to $35^{\circ} \mathrm{C}$, the MHPs operate to the highest thermal power and the temperatures increase up to $36{ }^{\circ} \mathrm{C}$ in buffer storage 1 . Also, the buffer storage 2 is charged, as shown in Figure 15 and the temperatures increase up to $34^{\circ} \mathrm{C}$.
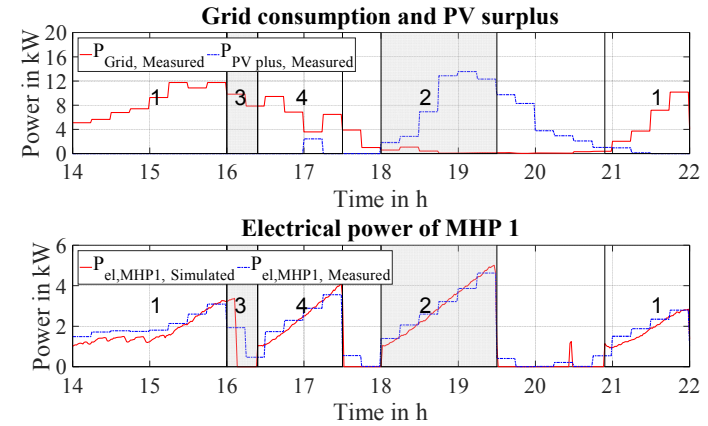

Figure 13: Grid consumption and PV surplus as well as the electrical power of MHP 1 in different operation modes.

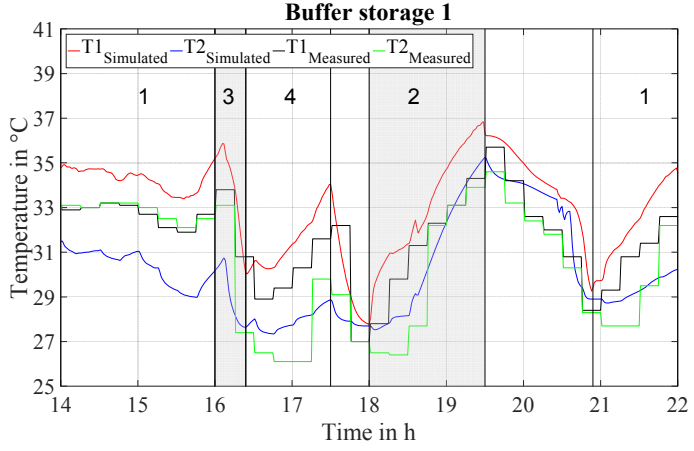

Figure 14: Temperatures in buffer storage 1 in different operation modes.

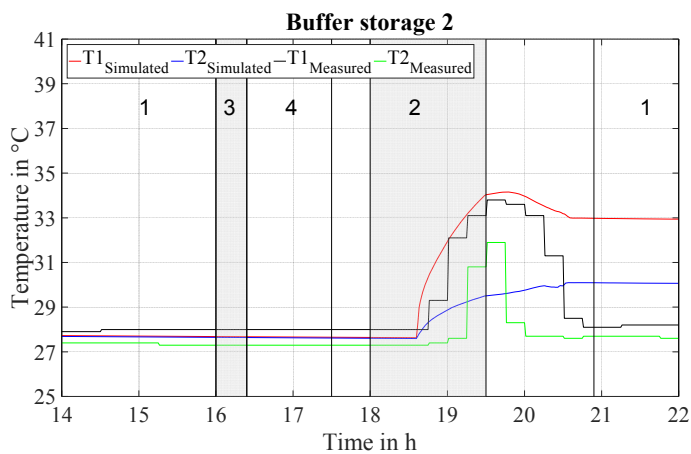

Figure 15: Temperatures in buffer storage 2 in different operation modes.

As there are solar measurements missing in this case, PV production is only measured and an input of the simulation. The comparison of the PV self-consumption (see Table 2) during the time period shows small differences. The PV self-consumption includes household and MHPs electricity.

Table 2: Comparison of PV self-consumption.

\begin{tabular}{|c|c|c|}
\hline Characteristics of MHP 1 & Measurement & Simulation \\
\hline PV production & $42.9 \mathrm{kWh}$ & $42.9 \mathrm{kWh}$ \\
\hline Direct PV of MHPs & $10.4 \mathrm{kWh}$ & $9.8 \mathrm{kWh}$ \\
\hline PV self-consumption & $32.9 \mathrm{kWh}$ & $32.3 \mathrm{kWh}$ \\
\hline
\end{tabular}

In general, the percentage of direct PV of the MHPs is $24.3 \%$ and the simulated percentage of direct PV of the MHPs is $22.8 \%$. Using a normal heat control of the MHPs, the percentage of direct PV is only $6.0 \%$.

\section{Results}

In this section, the measured and simulated results of the validation of the MHP model and the MHP System are compared regarding to the root-mean-square-deviation (RMSD), calculated with Equation 8. For a more general comparison, the normalized root-mean-square-deviation (NRMSD) is used, calculated in Equation 9. 


$$
R M S D=\sqrt{\frac{\sum_{i=1}^{n}\left(X_{\mathrm{Re} f, i}-X_{S i m, i}\right)^{2}}{n}}
$$

$$
N R M S D=\left(\frac{R M S D}{\left(X_{\mathrm{Re} f, \max }-X_{\text {Sim, min }}\right.}\right)
$$

The input data of the MHP model are measured temperatures of condenser and evaporator as well as the modulation speed. The results of the MHP model are outlet temperature of condenser and evaporator as well as thermal and electrical power. The simulated results are compared to the measured results of the MHP 1 and 2 by calculating the RMSD as well as the NRMSD and can be seen in Table 2 for MHP 1 and in Table 3 for MHP 2.

The RMSD value for the thermal power of MHP 1 is $1.2401 \mathrm{~kW}$ and for MHP 2 is $0.8569 \mathrm{~kW}$. The higher RMSD value of MHP 1 is an effect of the different measured mass flow rates at condenser for the same frequency, shown in Figure 7. This lead to the higher thermal power of MHP 1 (see Figure 8). There might be measuring inaccuracies and errors during the measurement of the MHP 1. This leads to deviations between measured and simulated thermal power of the two MHPs. For further research work, the measured mass flow rate is compared at other time periods.

The RMSD of electrical power is for both MHPs nearly the same value and leads to deviations of $0.3658 \mathrm{~kW}$ and $0.4078 \mathrm{~kW}$. The measured electrical power includes also the auxiliary power of the control unit and other electrical components of the MHP. This might explain the deviation to the simulation results.

For the condenser temperature, the RMSD is quite similar, as well as the RMSD of the evaporator temperature.

Table 2: Validation data of the MHP $1-R M S D$ and NRMSD values.

\begin{tabular}{|c|c|c|}
\hline Characteristics of MHP 1 & RMSD & NRMSD \\
\hline Thermal power & $1.2401 \mathrm{~kW}$ & $7.7 \%$ \\
\hline Electrical power & $0.3658 \mathrm{~kW}$ & $7.9 \%$ \\
\hline Condenser temperature & $0.5911 \mathrm{~K}$ & $5.1 \%$ \\
\hline Evaporator temperature & $0.6184 \mathrm{~K}$ & $8.0 \%$ \\
\hline
\end{tabular}

Table 3: Validation data of the MHP 2-RMSD and NRMSD values.

\begin{tabular}{|c|c|c|}
\hline Characteristics of MHP 2 & RMSD & NRMSD \\
\hline Thermal power & $0.8569 \mathrm{~kW}$ & $5.4 \%$ \\
\hline Electrical power & $0.4078 \mathrm{~kW}$ & $7.6 \%$ \\
\hline Condenser temperature & $0.4247 \mathrm{~K}$ & $3.7 \%$ \\
\hline Evaporator temperature & $0.5450 \mathrm{~K}$ & $5.0 \%$ \\
\hline
\end{tabular}

The input data of the MHP System are measured temperatures of evaporator as well as the modulation speed. The condenser inlet temperature is an input from the storage model (Type 534). The results of the MHP System are outlet temperature of condenser, buffer storage temperatures and supply temperature of the building load. The simulated results compared to the measured results of the MHP System by calculating the RMSD as well as the NRMSD and can be seen in Table 4. Condenser temperature of MHP 1 and MHP 2 have a higher RMSD than in the validation of the MHP model. This is an effect of the higher RMSD of the temperatures in the buffer storage units because the condenser inlet temperature of the MHP model is an input from the storage model. The buffer storage temperatures have a RMSD up to $2.3831 \mathrm{~K}$ at the bottom temperature of buffer storage 1 . The course of the supply temperature of the building load is quite accurate, but during a time period of hour 8 until hour 14, there are obvious deviations and that leads to a RMSD of $0.8380 \mathrm{~K}$.

The RMSD of the direct PV usage is 0.2284 that results in a NRMSD of $2.25 \%$. The RMSD of the PV selfconsumption is the same, as the electricity of the household a measured data and stays the same in both cases. However, the NRMSD reduces to $1.65 \%$.

Table 4: Validation data of the MHP System-RMSD and NRMSD values.

\begin{tabular}{|c|c|c|}
\hline $\begin{array}{c}\text { Characteristics of MHP } \\
\text { System }\end{array}$ & RMSD & NRMSD \\
\hline $\begin{array}{c}\text { Condenser temperature of } \\
\text { MHP 1 }\end{array}$ & $1.6449 \mathrm{~K}$ & $14.3 \%$ \\
\hline $\begin{array}{c}\text { Condenser temperature of } \\
\text { MHP 2 }\end{array}$ & $1.7865 \mathrm{~K}$ & $15.7 \%$ \\
\hline $\begin{array}{c}\text { Top temperature of buffer } \\
\text { storage 1 }\end{array}$ & $1.9069 \mathrm{~K}$ & $21.9 \%$ \\
\hline $\begin{array}{c}\text { Bottom temperature of } \\
\text { buffer storage 1 }\end{array}$ & $2.3831 \mathrm{~K}$ & $28.0 \%$ \\
\hline $\begin{array}{c}\text { Top temperature of buffer } \\
\text { storage 2 }\end{array}$ & $1.8245 \mathrm{~K}$ & $29.4 \%$ \\
\hline $\begin{array}{c}\text { Bottom temperature of } \\
\text { buffer storage 2 }\end{array}$ & $1.1074 \mathrm{~K}$ & $24.1 \%$ \\
\hline $\begin{array}{c}\text { Supply temperature of } \\
\text { building load }\end{array}$ & $0.8380 \mathrm{~K}$ & $7.2 \%$ \\
\hline
\end{tabular}

Table 5: Validation data of the PV Self-ConsumptionRMSD and NRMSD values.

\begin{tabular}{|c|c|c|}
\hline Characteristics & RMSD & NRMSD \\
\hline Direct PV of MHPs & $0.2284 \mathrm{~kW}$ & $2.25 \%$ \\
\hline PV self-consumption & $0.2284 \mathrm{~kW}$ & $1.65 \%$ \\
\hline
\end{tabular}

\section{Conclusion}

This paper presents an approach to control a MHP and a MHP System in simulation and in real application. In previous research work a DMS (Dentel et al., 2017) was developed for the MHP Energy System in simulation studies, but for the implementation in real application at terraced houses inputs and parameters are changed. Thus, the changed control strategy, the PV optimized control, is realized in the MHP Energy System in the terraced houses. The implemented PV optimized control is re- 
implemented in simulation and is validated with measuring points from the real MHP Energy System in the terraced houses. There are a validation of the MHP model and a validation the MHP System model that includes two buffer storage tanks and the building load.

The results of the validation for the MHP model show a good accordance to the thermal and electrical power. The NRMSD of the thermal power is between $5.4 \%$ and $7.7 \%$. The NRMSD of the electrical power is between $7.6 \%$ and $7.9 \%$. One of the two MHPs has a higher RMSD of $1.2401 \mathrm{~kW}$ for thermal power, which might come from measuring inaccuracies and errors during the measurement of the condenser mass flow rate. The higher measured values for the mass flow lead to a higher thermal power of MHP 1. For further research work, the measured mass flow rate is compared at other time periods. The temperatures of condenser as well as the temperatures of evaporator are quite correct with measured and simulated results.

The results of the validation for the MHP System show moderate accordance to the condenser temperatures. The measured temperatures of the buffer storage units are within the simulated results, but regarding the NRMSD, the deviations are between $15.7 \%$ and $29.4 \%$. The measured and simulated supply temperatures of the building load are quite similar.

The 4 operation modes of the PV optimized control are implemented and realized in simulation and real application. The comparison show a clear assignment of the different modes. The NRMSD for direct PV usage is $2.25 \%$ and for PV self-consumption is $1.65 \%$. Comparing the PV optimized control to a normal heat control of the MHPs, the percentage of direct PV increases from $6.0 \%$ up to $22.6 \%$ in simulation.

In conclusion, the power outputs of the measured and simulated MHPs have moderate deviations, whose emergence in simulation and measurement must continue to be investigated. Nevertheless, the results of the comparison of the MHP model and MHP System, the supply temperature of the building load, shows a good accuracy for modelling the MHP System in simulation. The PV optimized control shows the potential to increase direct PV usage. In further work, more measurements will be evaluated for analysing the PV self-consumption in the terraced houses.

\section{Acknowledgement}

This paper represents results from the project "Herzo Base - Energiespeicherhaeuser - Ein energieflexibles Gebaeudekonzept von morgen" (FKZ 03ET1364A). The project is supported by the Federal Ministry for Economic Affairs and Energy on the basis of a decision by the German Bundestag.

\section{References}

Afjei, T. and M. Wetter (1997). TRNSYS Type 451 Vertical Borehole Heat Exchanger Model 2.4. Stuttgart: Transsolar Energietechnik GmbH.

Banister, C., Wagar, W. and Collins, M. (2014). Validation of a single tank, multi-mode solar-assisted heat pump TRNSYS model. Energy Procedia 48, 499-504.

Battaglia, M., Haberl, R., Bamberger, E. and Haller, M. (2017). Increased self-consumption and grid flexibility of PV and heat pump systems with thermal and electrical storage. Energy Procedia 135, 358-366.

Buderus, J. and Dentel, A. (2017). Generalization Approach for Models of Thermal Bufferr Storages in Predictive Control Strategies. Building Simulation 2017.

Dentel, A. and Betzold, C. (2017). Control Strategies for Geothermal Heat Pump Systems in Combination with Thermal and Electrical Storage Units. Building Simulation 2017.

Psimopoulos, E., Leppin, L., Luthander, R. and Bales, C. (2016). Control algorithms for PV and Heat Pump system using thermal and electrical storage. ISES International Solar Energy.

TRNSYS (2018). TRaNsient SYstems Simulation, Solar Energy Laboratory, University of MadisonWisconsin. Version 18.1.

Wirth, H. (2018). Recent Facts about Photovoltaics in Germany. Fraunhofer ISE. 